\title{
Paisagens Informação: 0 Efeito das Tecnologias Digitais na Arte Contemporânea
}

\section{Landscapes Information: The Effect of Digital Technologies in Contemporary Art}

\begin{abstract}
Resumo: Este artigo elabora alguns questionamentos sobre a produção subjetiva na interface das tecnologias digitais e analisa o modo como tais tecnologias têm sido apropriadas pelo campo da arte. Intervenções em arte cada vez mais tecnológicas e inusitadas possibilitam compreender os efeitos nos modos de produção de subjetividade que surgem em reformulações referentes ao corpo, ao sujeito e a consciência colocando em xeque tais noções forjadas na modernidade. Para operar tal análise produzimos um diálogo com o pensamento de Gilbert Simondon, tomando como condutor seu conceito de Informação, concebido como um modo de organização, nunca relativo a uma realidade única e homogênea. Ao buscar novas bases para o problema do sujeito contemporâneo Simondon nos auxilia a construir uma noção de produção de subjetividade aonde as percepções de mundo são sempre parciais e mutáveis sujeitas ao encontro que estabelecem, neste caso, com as tecnologias adotadas pelo campo da arte tecnológica.
\end{abstract}

Palavras-chave: Arte. Tecnologia. Informação. Subjetividade. Individuação.

Abstract: This article presents some questions about the production of subjectivity in digital technology interfaces and examines how these technologies have been appropriated by the art field. Intervention processes in art which are increasingly technological and unusual to undertand the possible effects on the modes of production of subjectivity in some notions forged in modernity which concern to the ways of producing subjectivity related to the body, the subject, the consciousness have been questioned. In order to operate this analysis we have produced a dialogue with Gilbert Simondon, mainly his concept of information, which the author understands as a way of organization, never as single, homogeneous reality. Simondon helps us to build a concept of the of subjectivity production considering the contemporary subject which dwells in these interfaces of art and technology. These perceptions of the world, that we have called landscapes, are always partial and subject to the encounters with electronic art, that is being discussed in this text.

Keyword: Art. Technology. Information. Subjectivity. Individuation.

SPOHR, Fúlvia da Silva; BIAZUS, Maria Cristina Villanova. Paisagens Informação: o efeito das tecnologias digitais na arte contemporânea. Informática na Educação: teoria e prática, Porto Alegre, v. 17, n. 1, p. 77-90, jan./jun. 2014.

\section{Fúlvia da Silva Spohr}

Rede Gaúcha de Ensino Superior a Distância

Maria Cristina Villanova Biazus

Universidade Federal do Rio Grande do Sul

\section{A arte tecnológica e multimídia}

0 campo da Arte hoje é cada vez mais associado ao uso de linguagens multimídia (audiovisual, informática e telemática), robótica e da ampla manipulação digital e eletrônica na constituição de seus processos. Michael Rush (2006), em um estudo sobre as novas mídias na arte contemporânea, indica que a tendência das práticas artísticas tem sido cada vez mais a incorporação digital. O autor aborda questões referentes à arte na era tecnológica apontando a dificuldade de traçar a história e a caracterização dos novos meios de expressão em arte, visto sua constante modificação e agregação simultânea às novas mídias. Rush (2006) nomeia a absorção das novas mídias pela arte como "Arte Digital" (2006, p. 162) e reflete sobre o final dos "ismos" associados 
à arte do século XX - cubismo, surrealismo, conceitualismo, etc. (p. 162) indicando que na atualidade qualquer descrição de produção de arte que não dê espaço ao tecnológico está incompleta. A chamada Arte Tecnológica ${ }^{1}$, Arte Eletrônica ou ainda Arte Digital faz uso das mais diversas mídias como suporte para suas obras. A arte tecnológica designa as produções artísticas que utilizam as TIC - tecnologias da informação e comunicação como meio para sua criação. A arte tecnológica engloba uma variedade de manifestações artísticas que vão desde a arte interativa, nano arte, games, arte sonora, videoarte, a arte digital, web arte, instalações, performances, realidade virtual e aumentada, dispositivos interativos, ciberarte, telemática, cinema digital, pintura digital, pixel art, etc.

Quer sejam obras que utilizam o recurso digital para a criação de experiências estéticas em espaços virtuais, obras que exploram efeitos como recurso de edição, forma e cor como no caso da videoarte, performances que envolvem a projeção de imagens e vídeos ou ainda instalações montadas com recursos digitais como computadores e sensores, em todas estas modalidades artísticas encontra-se presente, atualmente, a idéia de que para a obra ganhe existência ela necessita da interação do público. Em muitas destas obras o público interage por meio de interfaces como mouse ou controles, luvas, sensores, etc. Tais manifestações artísticas tem sido objeto de estranhamento por grande parte do público em geral, uma vez que provocam experiencias sensório-

\footnotetext{
1 Não existe um consenso com relação à nomenclatura e a conceituação deste tipo de obra artística, vista a ampla gama de processos que incluem o uso de tecnologias em arte. Por este motivo adotamos como conceito de Arte Tecnológica toda e qualquer obra de utilize como suporte/interface as TIC - tecnologias da comunicação e informação. Rush (2006) analisa as novas mídias na arte contemporânea caracterizando algumas de suas manifestações. (RUSH, Michael. Novas mídias na arte contemporânea. São Paulo: Martins Fontes, 2006).
}

-motoras interativas bem diferentes daquelas produzidas pela contemplação da arte moderna ${ }^{2}$. Esse deslocamento acaba por implicar na produção de novos paradigmas estéticos a partir do encontro com objetos estéticos efêmeros, muitas vezes sem existência física concreta e definida que modificam nossas relações com o espaço físico e o virtual e também com os limites do corpo humano.

Há uma tendência à interatividade presente na nova paisagem da arte contemporânea, trazendo consigo novos modos de comunicação e de relação que possibilitam interagir, agir, modificar e intervir (com) as obras. Trata-se de obras estruturadas a partir de base de dados audiovisuais e multisensoriais, que buscam por vezes mobilizar e estimular os sentidos (visão, audição, paladar, olfato e tato). Hoje, não podemos mais considerar o público somente como espectador em arte. Com a possibilidade de participação nas obras tecnológicas surge o conceito de Interator que é aquele segundo Sobage (2008) que participa da obra não só através de sua interpretação ou reflexão mental, mas também a partir de sua atuação corporal (p.1988). Oliveira e Hildebrand acrescentam que "esta atuação na obra não se restringe a uma ação definida a priori, como apertar um botão, mas uma ação de experimentação ao nível molecular dos corpos ou elementar dos objetos tecno-estéticos, uma ação de agenciamentos" (OLIVEIRA; HILDEBRAND, 2010, p. 1031).

No entanto a possibilidade de manifestação de novos possíveis a partir da interação com as linguagens atuais da arte não garante que

\footnotetext{
${ }^{2}$ Arte moderna é adotada aqui como um termo genérico e que se refere à maior parte da produção artística do período que antecede a arte contemporânea (final do século XIX até meados dos anos 60. Este tipo de arte traz consigo certa noção de realidade, produzindo uma dicotomia entre sujeito e objeto considerados aqui como polos pré-existentes ao processo de conhecer.
} 
o caráter experimental de tais intervenções produza outros entendimentos com relação às coisas do mundo. Rolnik, ao comentar sobre a potência da arte enquanto catalisadora de uma experiência estética afirma que

Para que este processo se oriente por uma ética de afirmação da vida é necessário construir territórios com base nas urgências indicadas pelas sensações - ou seja, os sinais da presença do outro em nosso corpo vibrátil. É em torno da expressão destes sinais e de sua reverberação nas subjetividades que respiram o mesmo ar do tempo que vão se abrindo possíveis na existência individual e coletiva (ROLNIK, 2006. p. 10).

Pensando a partir de trabalhos em arte que se ocupam em produzir intervenções mediadas pelas novas características tecnológicas e eletrônicas, tais como: a interatividade, a artificialidade, a imersão, a inteligência artificial ou ainda a vida artificial, nos perguntamos se é possível produzir nessa interface algum tipo de experiência que convoque o sensível, indo além da política que rege os processos de produção de sentido? O processo de convocação do sensível em nosso entendimento é provocado quando ocorre uma crise em nossas referencias formais e em nosso entendimento da realidade. Rolnik nos auxilia a compreender esse fenômeno, complementando que é o mal-estar da crise que desencadeia o trabalho do pensamento (ROLNIK, 2006, p. 1).

Atualmente grandes eventos mundiais ${ }^{3}$ como o FILE - Electronic Language Internacional Festival, o Ars Electronica, a Conferência

\footnotetext{
${ }^{3}$ Alguns dos grandes eventos a nível mundial em arte eletrônica e digital que ocorrem na atualidade são: FILE - Electronic Language Internacional Festival, ver em: http://file.org. br/?lang=pt e o Ars Electronica: http://www.aec.at/prix/, a Conferência Anual da Sociedade Internacional de Artes Eletrônicas -ISEA http://www.isea-web.org/ e ainda o Emoção Art.ficial - Bienal Internacional de Arte e Tecnologia ver em: http://www.emocaoartficial.org.br/pt
}

Anual da Sociedade Internacional de Artes Eletrônicas -ISEA ou ainda o Emoção Art.ficial Bienal Internacional de Arte e tecnologia entre outros, tem se ocupado em promover a arte tecnológica apresentando artistas multimídia que exploram cada vez mais diferentes linguagens na produção de suas poéticas. No Brasil a arte tecnológica e multimídia ganha espaço a partir dos anos 1970 deslocando as produções de um tipo de arte com bases plásticas e físicas para outro tipo pautada por um fenômeno de desmaterialização da arte, ou seja, a matéria prima das obras já não é mais tão palpável como a tinta em uma pintura ou ainda o gesso ou a pedra sabão em uma escultura, mas produzida a partir de uma base imaterial. A destituição de referenciais físicos torna a experiência estética um grande fluxo de informações. Essa mudança produz um novo paradigma aonde o conteúdo das obras é antes de tudo informacional.

É fundamental a compreensão desse deslocamento no campo contemporâneo das artes, pois como nos diz Rolnik "a arte é uma prática de problematização: decifração de signos, produção de sentido, criação de mundos" (ROLNIK, 2002 p. 3-4).

Com efeito, a arte e a tecnologia seguem conjugadas atualizando-se em obras criadas a partir de plataformas digitais, que convergem as mais diferentes mídias. A arte produzida com ferramentas digitais redimensiona não só o campo da estética e da tecnologia, produzindo múltiplas linguagens, mas produz novos modos de subjetividade e de apreensão da realidade que modificam as relações consigo mesmo e com o mundo. A arte, assim como as ciências, corroboram para a criação de modelos de realidade, servindo como potente dispositivo de pensamento. Compreende-se, portanto, que através das intervenções 
em arte digital seja possível produzir certos deslocamentos na produção de conhecimento contribuindo para que modalidades de ruptura possam emergir do encontro com determinadas obras. Em nosso entendimento esta relação poderá ocorrer não somente por meio de estímulos sensoriais, mas a partir do encontro com o campo do sensível, ou seja, por afetação, deslocando a experiência estética para a própria experiência em $1^{\text {a }}$ pessoa, encarnada e não para uma explicação sobre ela. Sobre isso Gianetti afirma que:

A recepção da arte assume uma relevância peculiar a partir da relação original entre as pessoas e as obras mediante interfaces técnicas. A realidade virtual, a vida artificial e a inteligência artificial como sistemas incorporados à arte pressupõem novas experiências participativas e interativas, que permitem integrar o espectador no contexto da obra. São modelos de um tipo de entorno tecnicamente ativado, no qual somos sempre parte do sistema que observamos e com que interagimos. O diálogo entre obra e espectador se estabelece não só sobre a base da linguagem ou da reflexão, mas, sobretudo, de uma maneira prática e intuitiva, no sentido circular da comunicação, na medida em que se estimula a própria ação do público no entorno da obra (GIANETTI, 2006, p. 6).

Analisando sob um ponto de vista de produção de subjetividades, cabe-nos perguntar no que implica o espectador/ interator ser considerado participante de uma obra? Ou ainda, qual a potência estética que experiências imersivas e/ou interativas promovem? Que desdobramentos são possíveis a partir destas práticas? Com relação à arte digital nosso posicionamento é de que no contexto de produção tecnológica contemporâneo, as interfaces, mídias e tecnologias digitais não encerram em si mesmas um caráter específico, elas são caminho para que experimentações do sensível ocorram. Acreditamos que a especificidade da arte tecnológica enquanto produção de linguagem e de pensamento desdobra-se em um possível deslocamento de uma arte-objeto para uma arte experiencial o que poderá ou não produzir diferença em uma rede de sentidos já estabelecida.

\section{Suportes e superfícies: por uma estética tecnológica}

A ciência, a arte e a tecnologia são capazes de modelar nossa visão e experiência de mundo. Segundo Sodré (2006, p. 45) o conceito de estética é designado como sendo a ciência do modo sensível de conhecimento de um objeto. Oriundo do grego aisthesis ou estética significa ainda sentir a partir de uma rede de percepções físicas e sensíveis, irredutível ao saber lógico (SANTAELLA, s/d, p.1). Austry e Bois (2008) contribuem para a compreensão deste tema ao considerar que o acesso ao sensível desvela um universo de tonalidades e de nuances que tomarão ora a forma de sensações cinéticas, forma de informações significantes, ou ainda a forma da tomada de consciência espontânea, indicando que a relação com o sensível dá acesso a um novo modo de conhecimento, ligado à sensação corporal. Também Rolnik nomeia o que entende sobre o campo das sensações ao dizer que "'Sensação'" é precisamente isso que se engendra em nossa relação com o mundo para além da percepção e do sentimento. Quando uma sensação se produz, ela não é situável no mapa de sentidos de que dispomos e, por isso, nos estranha" (ROLNIK, 2002, p. 3).

Peter Weibel em uma entrevista a revista digital INTERACT - Revista de Arte, Cultura e Tec- 
nologia, (maio de 2005), parafraseando Freud coloca "que a tecnologia é o meio que torna presente o que está ausente" (WEIBEL, 2005). Assim como o autor, entendemos que os dispositivos tecnológicos quando operam no campo das artes apresentam grande potencial para a criação de efeitos estéticos (SANTAELLA, s/d), que operam para além da representação a um nível simbólico, sendo capazes de acionar e mobilizar uma trama sensível e geradora de novos sentidos naqueles que compõem com a obra.

Porém é preciso olhar o fenômeno da arte tecnológica sem perder de foco sua hibridização com estéticas tecnológicas anteriores. Com maior ênfase ao longo da historia da humanidade o uso de tecnologia aparece entendido como o estudo e utilização de teorias e métodos científicos e de conhecimento técnico especialmente atrelados à solução e manutenção de problemas. Além dessa conotação o termo tecnologia aparece também como ferramenta, artefato e maquinário. A palavra tecnologia surge do encontro dos termos tecno, do grego techné, que é saber fazer, e logia, do grego logos, razão. Logo, nessa perspectiva tecnologia significa a razão do saber fazer.

A tecnologia, quando trazida à discussão, é na maioria das vezes remetida à idéia de aparato tecnológico a ser acessado na medida em que possa ser manipulado por aquele que dele se apropria enquanto conhecimento técnico. A vida humana é acompanhada por determinadas técnicas e tecnologias já há muitos séculos. O homem parece ter naturalizado grande parte delas, uma vez que, com o passar de gerações, muitas tornaram-se "invisíveis" por sua incorporação ao cotidiano. Sob esse aspecto, a explicação consiste em se referir que com o domínio da técnica, ou seja, com o acesso privilegiado a ela, pudéssemos dominá-la e dela fazer uso.
Acreditamos que a tecnologia assim como as instituições configuram os modos de viver não sendo meras ferramentas ou meios. À medida que a tecnologia é desenvolvida pelo homem, passa também a modificá-lo em sua relação com o mundo. Analisando o contexto da produção tecnológica de um modo geral e não somente no campo das artes, podemos destacar algumas tendências que descrevem a produção tecnológica de modos distintos. Com no caso da concepção instrumentalista, conforme classificação apresentada por Escóssia (1999), que nesta perspectiva, tecnologia diz respeito a um conjunto de meios e instrumentos neutros, a serviço e progresso da humanidade. Por outro lado, essa concepção co-existe com uma corrente que denomina e rejeita a tecnologia como anti-estrumentalista, argumentando que a técnica e a tecnologia possuiriam uma potencia autônoma. Ainda podemos lembrar uma concepção dromológica, que denomina a técnica unicamente a partir de uma lógica da velocidade, como no caso dos dispositivos com os quais convivemos e que de um momento para outro já parecem estar defasados. Podemos analisar ainda uma quarta concepção que compreende a técnica em uma dimensão ontogenética, ou seja, coletiva e processual, aonde o foco de analise é a relação que se estabelece com determinada tecnologia. Não buscamos afirmar uma destas concepções em detrimento de outra, pois estaríamos nos encerrando de forma hermética e ideológica. A questão, porém é podermos compreender essa complexidade de relações e critérios sob os quais operamos, no objetivo de desmistificar as noções de neutralidade ou tecnofobia. As diversas concepções da tecnologia surgidas na cultura humana são formalizações de relação consigo e com o mundo se atualizam também no campo das artes e da educação. 
Diante disso, inferimos que toda ação mediada pelas tecnologias digitais trata-se antes de tudo de uma ação ética, estética e política. Por exemplo, ao refletir sobre o modo como temos operado a tecnologia digital no campo da arte a partir de práticas distintas podemos gerar processos baseados em dominação, disciplina e representação, ou processos democráticos, de autoria e afirmação da vida.

\section{A Co-emergência de uma poética tecnológica: do visível ao invisível}

No conceito de Enação, desenvolvido por Francisco Varela (2003) o processo do conhecer, ou cognição é entendida como atuação, em um mundo vivido, constituído por modulações históricas sem determinações prévias, rompendo com o postulado de que conhecer é representar. Designando uma corporeidade, o corpo passa a ser entendido como contexto e lugar de inscrição da experiência.

Para Varela, a experiência é proveniente da integração entre diversos módulos cognitivos percepção, memória, emoções, temperamento, etc. Assim o meio não é instrutivo, ele perturba o sistema que, ao se auto-produzir em seu (ser e fazer), conhece, fazendo distinções neste meio. A ação de (saber-fazer) é uma experiência em $1^{a}$ pessoa criada no processo do viver a partir da história das conexões e encontros efetivados.

$\mathrm{Na}$ enação, o que faz diferença é o corpo em uma rede sensório motora. Os símbolos e as regras emergem a partir dos encontros são transformando em parte de um mundo de significação. Deste modo a cognição se dá em ato, dentro de um plano de estabilizações com atratores e atos recorrentes. Assim criam-se modos de fazer em comum, em relações sen- sório motoras compartilhadas em um modo de operar na linguagem. É na via enativa, (saber-fazer) quando o conhecimento é corporificado, que se apresentam novos possíveis problemas.

Uma ação incorporada não é algo que responde a um problema e a um estímulo, mas sim vai ao encontro deles. Portanto a ação enativa não é reativa e sim propositiva. A atenção, a inteligência e a própria percepção são efeitos do processo cognitivo, são emergência daquilo que em determinado momento pôde enatuar, não podendo ser tomada como estruturas anteriores ao próprio processo do conhecer.

A manutenção de nossas identidades e papéis no tecido social parece ser o centro da ação humana. A possibilidade de mantermos uma imagem estável de nos mesmos e dos outros afasta a possibilidade de configuração de novos contornos existenciais. Operamos por meio de nossos órgãos de sentido a partir de uma capacidade perceptiva a qual segundo Rolnik "nos permite apreender o mundo em suas formas para, em seguida, projetar sobre elas as representações de que dispomos, de modo a Ihes atribuir sentido" (ROLNIK, 2006, p. 2). Porém, agimos também ao nível invisível das sensações, que nos permite apreender o mundo por meio de experiencias sensíveis em nível de corpo e de energia. Com relação a essa afirmação Rolnik complementa que deste modo dissolvem-se as figuras de sujeito e objeto, e com elas aquilo que separa o corpo do mundo (ROLNIK, 2006, p. 3). A autora nomeia esta experiência de "corpo vibrátil", como sendo a capacidade de nossos órgãos dos sentidos em seu conjunto (percepção e sensação).

Uma das tentativas da arte tecnológica tem sido a de produção de uma nova economia cultural, baseada, como já dissemos, na interatividade com o público. Stiegler (2007) afirma que a arte não necessita compreensão, mas 
supressão e tempo. Os artistas surgem como pesquisadores e catalisadores de novas possibilidades de realidades a serem experimentadas, buscando produzir ações que potencializem o campo do sensível. Projetos em arte onde as interfaces das obras são apresentadas em interação por jogos eletrônicos, internet, vídeos, lasers, sensores de luz, recursos de mecatrônica, entre outros, tem sido cada vez mais difundidas.

A arte interativa implica em produzir obras que envolvam estratégias estéticas e comunicacionais intuitivas e abertas em interfaces convidativas à experimentação. Porém, disponibilizar formas, conteúdos e recursos, de modo a tornar mais imersiva à interação artística, não garante que uma experiência sensorial perceptiva produza algum tipo de deslocamento subjetivo. Este é um paradoxo, pois a cada novo estimulo produzido em conexão com os órgãos de sentido, é possível que haja um distanciamento da dimensão sensível e encarnada do conhecimento.

Temos assistido os universos da Arte e da educação, numa relação estreita cada vez mais povoada por tais recursos tecnológicos. Porém, em que medida as intervenções em arte tecnológica modificam as relações de aprendizagem consigo e com o mundo? Para que possamos contribuir com estes questionamentos é preciso definir alguns critérios conceituais a serem carregados em nossa caixa de ferramentas, os quais servirão com o suporte a criação de uma possível estratégia de mobilização da potência do pensamento/criação, que segundo Rolnik (2006) são intransmissíveis por meio das representações de que dispomos (p.4).

Independente da superfície aonde determinado saber é inscrito, este tomará a forma de um corpus tecnológico. A dimensão tecnológica entendida a partir da heterogeneidade da relação homem-técnica modifica os modos de subjetivação. Analisando com cuidado, a complexidade da relação tecnológica, efeitos sutis e subjetivos não parecem serem tão óbvios nem facilmente observados, provocando deste modo uma invisibilidade que não é legitimada.

Linguagens de programação, análises semióticas e de discurso, são de certo modo operadores que possibilitam criar analisadores simbólicos, ou seja, geram visibilidade por estarem circunscritos em sistemas de relações passiveis de serem codificados. Mas em se tratando de questões que estão colocadas anteriores ao campo descritivo da linguagem como a experiência estética que se dá de forma sensível e encarnada?

De certo modo, é possível argumentar com relação à fenomenologia da percepção e do sistema sensório-motor, que seja viável criar parâmetros de observação e análise, mediante a categorização de variáveis de controle, como vibração sonora, luz, temperatura, etc.

Porém, ao observarmos atentamente, aquilo que nomeamos como observação fenomenológica trata-se de uma descrição parcial, vista que enunciada por um observador imerso na linguagem. Estamos, pois, diante de mais um paradoxo, ao percebemo-nos parte de uma relação circular e auto-referente. Todavia a cada vez que estabelecemos uma relação de comunicação com o fora, ou seja, aquilo que nos parece chegar como estímulo externo, nossa produção cognitiva é acionada e operamos internamente nossas marcas mentais, nossa estrutura de marcas mentais e sensoriais produzimos uma experiência como externa a nós.

Deste modo o externo, ou seja, o campo da linguagem é efeito de um modo de operação intrínseco à experiência humana. O efeito dessa operatividade é deste modo atualizado num mundo externo. Não se trate de nos referirmos 
a um tipo de experiência de um "eu" ocorra de modo isolado, antes pelo contrário é pela possibilidade de ação no mundo fenomenológico que torna possível experimentar em um ato reflexivo esta experiência.

A tecnologia, em especial as mídias digitais, parecem carregar uma potência capaz de produzir deslocamentos em direção a experimentação de realidades possíveis. Medeiros parafraseia o que vem a ser tecnologia em sua concepção: "brilho dos olhos falando desejos de amor, a voz áspera ou doce, minha intuição são tecnologias" (MEDEIROS, 2005, p.4).

A experiência dualista de sujeito e mundo vivida como interna e externa, organiza sujeitos de forma passiva diante da possibilidade de liberdade de criação frente a uma existência pré-definida e acabada. Podemos entender que a tecnologia comporta em si, não um fechamento, mas sim uma estabilização de códigos de compartilhamento que não é acabada e por isso contém um universo de possíveis ainda não emergidos.

Esse deslocamento constante entre uma paisagem objetiva e subjetiva, que desestabiliza nossas referencias a todo instante invoca que recriemos a realidade inventando novos modos de expressão. Essas relações se estabelecem sempre em nível corporal. O corpo sempre está presente, não sendo possível deslocar a experiência sensível para além dele, ou seja, sua ocorrência é sempre situada e encarnada em $1^{a}$ pessoa. Desta forma inferimos que em nossa relação com o outro não trocamos ou emitimos algum tipo de informação, mas sim de sinais, expressos a partir da vibratibilidade do nosso corpo. Como afirma Rolnik "é necessário construir territórios com base nas urgências indicadas pelas sensações - ou seja, os sinais da presença do outro em nosso corpo vibrátil" (ROLNIK, 2006, p. 10).

\section{0 sujeito contemporâneo como fronteira}

\author{
"O sujeito da pele pra fora não \\ tem um lugar físico" \\ Cildo Meireles ${ }^{4}$
}

A modernidade trouxe consigo a idéia de certa política do corpo, centrando e atrelando o sujeito a idéia de corpo enquanto um lugar de verdade.

Podemos problematizar o lugar do sujeito na produção de subjetividade sob o pano de fundo das práticas em arte contemporânea. A arte tecnológica traz consigo uma problemática relativa ao corpo, uma vez que em muitos projetos a obra só acontece a partir do encontro com o interator. Esta dimensão corporal permite tensionar a lógica vigente que indica que as identidades são inerentes ao humano, que pode ser entendido em sua infinidade de características biológicas e comportamentais. Trazendo uma linha muito tênue entre por um lado a singularidade como pertencente ao sujeito e de outro o campo social.

Também entre os pensadores contemporâneos, surgiram muitos questionamentos com relação ao lugar do sujeito, como no campo da antropologia social, com Donna Haraway, que desenvolveu o Manifesto Cyborg, escrito na década de 80 definindo que um cyborg é um organismo cibernético, um hibrido entre organismo e máquina, uma criatura de realidade social, bem como de ficção (HARAWAY, 1994 , p. 244). Seu argumento sustenta, a partir de estudos sobre gênero, que esta é uma categoria construida socialmente. Sua leitura

\footnotetext{
${ }^{4}$ Esta é uma fala do artista Cildo Meireles concedida em entrevista à pesquisadora Tania Rivera em seu vídeo documentário chamado Ensaio sobre o sujeito na Arte Contemporânea Brasileira (documentário RJ, 2009, Direção de Tania Rivera).
} 
sobre o cyborg transgride estereótipos sobre gênero e consequentemente sobre a produção de subjtividade, ao levantas a questão sobre a construção social de conceitos como homem, mulher, corpo e o próprio conceito de humano. Haraway traz com essa provocação uma possibilidade de ruptura com dicotomicas instituidas tais como os conceitos de humano/ não-humano, cultura/natureza, masculino/ feminino, tecnologia/biologia, divino/humano, realidade/representação e por fim a dicotomia entre sujeito/objeto.

O campo das artes aliados a tecnologia e a biologia também tem se valido da idéia de organismo cibernético apresentando o hibrido homem-máquina para provocar questionamentos semelhantes. Como é o caso do artista performático e multimídia Stelarc ${ }^{5}$ e suas obras com próteses robóticas. Em um de seus trabalhos, Stelarc trás a publico um experimento com seu próprio corpo como suporte à obra, causando polêmica ao apresentar uma prótese de uma orelha humana cultivada e implantada em seu braço sob a pele. Para se ver diante de obras como as de Stelarc é preciso desarmar-se de qualquer leitura pronta. Na década de 70 o artista precocemente já desenvolvia um projeto chamado "Corpo Amplificado", no qual filmou seu esôfago e parte do intestino a fim de entender o funcionamento do corpo humano, imprimindo assim em seu trabalho uma dimensão não só estética, mas também filosófica e científica. Outro artista com obras com sistemas eletrônicos bastante interessantes é o brasileiro Eduardo Kac. Ele foi o primeiro homem a quem foi implantado um microship no calcanhar em um de seus projetos chamado Time Capsule, uma obra física na qual o local

\footnotetext{
5 Stelarc é o pseudônimo do artista performático australiano Stelios Arcadiou. Para conhecer a obra do artista visite seu website: http://stelarc.org/
}

é ao mesmo tempo o corpo do artista e um banco de dados ${ }^{6}$. Esta obra de Kac foi chamada como sendo uma obra-experiência, aonde ao se entrar na galeria onde a obra se realiza, o público encontra um médico e um leito hospitalar cercado por um computador on-line, por equipamento adicional de transmissão e um dedo tele robótico. O procedimento é concluído com a inserção de um microchip subcutâneo. A partir disso o implante é escaneado com um aparelho portátil gerando um sinal de rádio que energiza o microchip sendo registrado via web em um banco de dados.

Segundo o artista a motivação para esta obra ocorreu a partir de sua observação de que não é mais possível confiar à imagem o estatuto de agente de preservação da memória histórica ou pessoal. Além disso, a partir de intervenções cirúrgicas e da política de modificação dos corpos por meio de cirurgias plásticas é possível transformarmos a nos mesmo no que queremos, levantando assim um debate sobre a legitimidade desta ação enquanto manifestação estética e obra de arte e ainda suas implicações éticas em diferentes campos. Obras como estas tem um cunho extremamente político, uma vez que produzem estranhamento favorecendo que se modifique a subjetividade desatrelando-a de uma noção de identidade. Não basta encontrar-se com a obra, é preciso compor com ela, estar aberto a sua capacidade de desterritorialização, adotando um olhar estrangeiro para as coisas do mundo.

Outro artista multimídia é o venezuelano Ernesto Klar, que reside e leciona na cidade de Nova Iorque. Seu trabalho explora o potencial poético de revelar e transformar o imperceptível. Entre as obras de Klar destacamos a instalação interativa audiovisual chamada "Luzes

\footnotetext{
${ }^{6}$ A descrição da obra Time Capsule de Eduardo Kac encontra-se disponível on line em: http://www.ekac.org/kactimbr.htm
} 
relacionais" (2009-2010) na qual o artista explora a relação entre o espaço e as pessoas. A obra utiliza luz, som, neblina e um sistema de software customizado para criar um espaço-luz tridimensional onde o interator participa com sua presença e movimento corporal. Segundo o artista, "Luzes Relacionais" é uma homenagem à obra e à pesquisa estética da artista brasileira Lygia Clark ${ }^{7}$ e impulsiona seu interator a construir um processo relacional com o espaço. Rolnik aponta para o cuidado que precisamos ter ao analisar tais práticas em arte, referindo que... "o convite à mobilização daquilo que se move por trás da coisa corporal como elemento decisivo da obra não pode ser confundido com o convite à participação do espectador e à manipulação por ele dos objetos criados pelo artista" (2005, p. 4). Acrescenta a necessidade de estabelecer tal distinção, ao referir certo fascínio contemporâneo pela "interatividade", a qual costumamos qualificar como "relacional", mas que de fato, encontra-se, segundo a autora, "na fachada das coisas e de nossos próprios corpos", e não por trás e através deles (p.4) em um caráter de entretenimento e distração e não enquanto potência para o sensível.

Segundo Simondon o acontecimento, ou individuação como apresenta em sua teoria, não se dá no indivíduo, mas no sujeito entendido como teatro de individuação (SIMONDON, 2009, p. 30) fronteira, ou ainda, como um modo de organização, diferente da relação entre sujeito e objeto enquanto polos distintos. Algumas, porém não todas as obras tecnológicas, como as apresentadas anteriormen-

\footnotetext{
7 Lygia Clark (1920-1988) é uma artista da arte de vanguarda brasileira e referência mundial especialmente pela última fase de sua obra intitulada Objetos Relacionais. O percurso da artista fez parte de um movimento crítico desenvolvido entre os anos 60 e 70. O web site que apresenta e dissemina a obra da artista está disponível em: http://www.lygiaclark.org.br/ defaultpt.asp
}

te, fomentam a possibilidade de se estar no mundo de uma maneira humana, mas também crítica, afirmando o poético da vida, enquanto potência, deslocando-se do discurso de uma sociedade identitária para explorar o campo do sensível. Essa ação ética no mundo trata-se de um cultivo onde a cada instante é preciso deslocar-se em si mesmo entre o campo das percepções validadas pelo discurso vigente e hegemônico em direção ao campo das sensações que é da ordem dos afetos.

\section{Paisagem informação: um diálo- go com Gilbert Simondon}

Gilbert Simondon nos oferece algumas pistas, para entender o lugar do sujeito no contemporâneo entre elas a idéia de que é preciso deslocar-se da noção de forma para a de informação para a compreensão dos processos de individuação. A noção de um "eu", indivíduo constituído a partir de uma política do corpo gera e alimenta um esquema de pensamento que privilegia a crença na existência e na estabilidade desse indivíduo. Esse esquema induz o pensamento a uma atenção excessiva à individualidade constituída, amarrando-a a um princípio de identidade capaz de reunir multiplicidades em unidades supostamente reconhecíveis, não-divididas, estáveis. Ao analisar a história da filosofia ocidental, Simondon pensa a problemática do sujeito a partir da análise dos sistemas metaestáveis que são irredutíveis à ordem da identidade. Simondon nos diz:

Existem duas vias segundo as quais a realidade do ser como indivíduo pode ser abordada: uma via substancialista, considerando o ser como consistindo em sua unidade, dado a si mesmo, fundado sobre si mesmo, inengendrado, resistindo àquilo que não é ele mesmo; 
uma via hilemórfica considerando o indivíduo como engendrado pelo encontro de uma forma e de uma matéria. [...] mas há algo de comum nessas duas maneiras de abordar a realidade do indivíduo: ambas supõem que existe um princípio de individuação anterior à própria individuação, suscetível de explicá-la, de produzi-la, de conduzi-la. A partir do indivíduo constituído e dado, esforça-se para remontar às condições de sua existência (SIMONDON, 2009, p. 23).

O autor sinaliza que é preciso pensar em nível de operação de individuação e não no individuo com suas características intrínsecas. Assim o sujeito passa a ser entendido a partir de sua realidade relativa, sempre parcial e inacabada. Simondon acrescenta que o indivíduo é relativo em dois sentidos: "pois ele não é todo o ser e porque ele resulta de um estado do ser no qual ele não existia nem como indivíduo e nem como princípio de individuação" (SIMONDON, 2009, p. 26). Além disso, com a contribuição do pensamento do autor é possível desmistificar a noção de estabilidade e equilíbrio como sendo formas naturais de manutenção da vida. Pelo contrário, o autor analisa os sistemas físicos verificando que a metaestabilidade é o motor propulsor destes processos, ao apresentar "a individuação física como um caso de resolução de um sistema metaestável" (SIMONDON, 2009, p. 28).

O autor coloca ainda que a individuação não é o encontro de uma forma e de uma matéria, mas a mediação, a resolução surgida no interior de um sistema metaestável e rico em potenciais. No caso dos seres vivos, aponta que a individuação não é definitiva, mas perpetuada ao longo da vida, aonde o sujeito não é somente resultado de uma operação de individuação, mas teatro de individuação (SIMONDON, 2009, p. 30). Esse posicionamento implica em reformular a pergunta sobre o que é conhecer anterior à estrutura de qualquer significação ou identificação e também a noção de sujeito como transcendente à própria operação de individuação que segundo o autor provem de perspectivas que pressupunham a existência "de um princípio de individuação anterior à própria individuação, suscetível de explicá-la, de produzi-la, de conduzi-la" (SIMONDON, 2009 , p. 23). Trata-se, portanto de incluir a atenção a si, como modo de tornar a experiência de um mundo externo possível. A tomada de consciência do corpo como plano de registro e inscrição da aprendizagem ocorre como emergência da percepção e da noção de um self.

Deste modo entendemos que as formas ganham materialidade a partir das ações perceptivas e sensoriais aonde imagem e som tem sentido somente em uma rede de interfaces, composta por humanos e máquinas. Nessa ecologia, o terreno das sensações suscitadas pelo encontro com obras tecnológicas e interativas ocorre como ação encarnada aonde o corpo é o próprio plano de inscrição. Neste caso a informação segundo o autor seria a tensão entre duas realidades díspares, o encontro do corpo com um sinal seja visual, sonora, etc., servindo como um detornador de individuação. Além disso, não havendo uma unidade e identidade da informação, uma vez que não se trata de um termo; ela supõe sempre um tensionamento, inerente a uma problemática. Simondon acrescenta que a informação está sempre no presente, atual, pois ela é o sentido segundo o qual um sistema se individua (SIMONDON, 2009, p. 36).

A contribuição do pensamento de Simondon opera como propositor de uma dimensão problematizadora que compreende a experiência subjetiva enquanto a incompatibilidade de um sistema não resolvido, mas em devir; 
um vir a ser sempre inacabado e em vias de uma nova resolução. Não se trata, portanto, de captar informações imagéticas ou sonoras de um mundo, mas, a partir de uma experiência de mundo produzi-las como resultantes da própria operação de problematização. Neste sentido as intervenções em arte tecnológica podem oferecer uma potencia de invenção ao entender a percepção não como a apreensão de uma forma estabelecida, mas sim a invenção da mesma, aonde os estímulos servirão como propulsores para a solução parcial de conflitos e tensionamento, modificando não só a relação sujeito e objeto como também sua própria estrutura.

A experiência estética deste modo não ocorre somente a partir da produção em uma rede de sentidos, ela também ocorre em níveis mais sutis. Essa dimensão de afecção não pode ser manifesta como enunciado no momento de sua manifestação. Somente é passível de reformulação enquanto reflexão, aonde a retomada da experiência pela explicação configura-se, como um reconhecimento. Ao discorre sobre o tema da cognição, Kastrup nos auxilia a pensar quando refere:

O que sublinho é absoluta recusa do caráter inventivo da cognição, que é deixado de lado como um resto, como o principal resíduo da produção crítica. É a negação de que suas condições de exercício estejam sujeitas à transformação, que possam surgir novas regras de funcionamento que criem outras formas de conhecer. Não se trata de operar somente dentro de uma invenção da cognição. O processo de reconhecimento é necessário para que possamos operar na linguagem, de modo que possamos criar congruências operacionais que só se estabelecem como linguajar e emocionar em uma rede recursiva. Assim, a cognição é vista, por seu caráter inventivo definida como a potência que tem de diferir de si mesma (KASTRUP, 1999, p. 45).
O que apontamos com isso, é que a experiência estética se dá quando a cognição se racha, permitindo novas operatividades. Esse efeito possibilita novos arranjos cognitivos, passiveis de problematização e reordenamento, contribuindo na constituição de significações. Assim, ao inclui a dimensão sensível no processo de produção de subjetividade apostamos que uma obra tecnológica possa servir como dispositivo de convocação do sensível ampliando as chances de novas produções de sentido.

Portanto ao pensarmos novas bases para o problema do sujeito no contemporâneo, Simondon nos auxilia a construir uma noção de processo de produção de subjetividade aonde as percepções de mundo, entendidas aqui como paisagens, são sempre parciais e mutáveis sujeitas ao encontro que estabelecem, neste caso, com as tecnologias adotadas pelo campo da arte tecnológica multimídia digital e eletrônica. A interface com dispositivos tecnológicos e eletrônicos em arte podem, portanto deslocar a impressão de realidade na passagem entre um campo problemático a outro distribuindo-se em resolução parciais. Ao produzir estranhamento com a obra aonde a cada novo encontro a (re)colocação de problemas possibilite um alargamento da própria experiência que ela oferece, num movimento de problematização das formas constituídas (KASTRUP, 1999), nos domínios objetivo e subjetivo.

Sob a ótica de Simondon, a relação entre obra e interator não pode ser entendida como a relação entre dois entes com existências separadas, mas como um campo de forças heterogêneo e problemático em um movimento de subjetivação-objetivação. Para tanto é necessário deslocar a noção de identidade em direção a abertura de um campo sensível, imperceptível e imanente, fluxo contínuo de in- 
formações que se manifestam. Espera-se com isso que se desnaturalizem as paisagens de mundo entendidas enquanto "forma".

Nessa perspectiva, a pergunta pelo sujeito não é mais substancialista, a partir da forma de um "eu", mas entendida enquanto processo que engloba o corpo individuado e as formações e estruturas parcial do mundo. No mo- mento de relação com uma obra e todas as tecnologias envolvidas nela, a mesma passa a ganhar existência, distinguindo-se do entorno e tomando forma, a partir da percepção enquanto campo pré-individual em uma experiência sensível não minha, mas em composição com a carne do mundo.

\section{Referências}

BOIS, Danis; AUSTRY, Didier. A emergência do paradigma do sensível. Revista @mbienteeducação, v. 1, n. 1, jan./jul. 2008. Disponível em: http://www.cidadesp.edu.br/old/revista_educacao/index. html. Acesso em: 21 jun. 2013.

ESCOSSIA, Liliana. Relação homem-técnica e processo de individuação. Sergipe: Editora UFS, 1999.

GIANETTI, Claudia. Estética Digital: Sintopia da Arte Ciência e Tecnologia. C/Arte: Belo Horizonte, 2006.

HARAWAY, Donna. Um manifesto para cyborgs: ciência, tecnologia e feminismo socialista na década de 80. In: Tendências e impasses: o feminismo como crítica da cultura. Heloisa Buarque de Hollanda (Org.). Rio de Janeiro: Rocco, 1994, p. 243-288.

KASTRUP, Virgínia. A invenção de si e do mundo: uma introdução do tempo e do coletivo no estudo da cognição. Campinas: Papirus.1999.

MEDEIROS, M. B. Aisthesis: Estética, educação e comunidades. 1. ed. Chapeço: ARGOS, 2005.

OLIVEIRA. A. M.; HILDEBRAND, H. Uma concepção sistêmica da obra de arte na contemporaneidade. $19^{\circ}$ ENCONTRO DA ANPAP. Bahia, 2010. Disponível em: http://www.anpap.org.br/anais/2010/ pdf/cpa/andreia_machado_oliveira.pdf. Acesso em: 26 jun. 2013.

ROLNIK, Suely. Afinal o que há por trás da coisa corporal? 2005. Disponível em: http://www. pucsp.br/nucleodesubjetividade/suely\%20rolnik.htm. Acesso em: 26 jun. 2013. 
Subjetividade em Obra. Lygia Clark, artista contemporânea. 2002. Disponível em: http:// www.pucsp.br/nucleodesubjetividade/suely\%20rolnik.htm. Acesso em: 22 jun. 2013.

Geopolítica da cafetinagem. 2006. Disponível em: http://www.pucsp.br/nucleodesubjetividade/suely\%20rolnik.htm. Acesso em: 24 jun. 2013.

RUSH, Michael. Novas mídias na arte contemporânea. São Paulo: Martins Fontes, 2006.

SANTAELLA Lucia. As imagens no contexto das estéticas tecnológicas. Online. http://www.arte. unb.br/6art/textos/lucia.pdf. s/d. Acesso em: 24 jun. 2013.

SIMONDON, Gilbert. La individuación a la luz de las nociones de forma y de información. 1. ed. Buenos Aires: Ediciones La Cebra y Editorial Cactus, 2009.

SODRÉ, Muniz. Estratégias sensíveis. Afeto, mídia e política. Rio de Janeiro: Vozes, 2006.

SOGABE, M. O espaço das instalações: objeto, imagem e público. $17^{\circ}$ ENCONTRO NACIONAL DA ASSOCIAÇÃO NACIONAL DE PESQUISADORES EM ARTES PLÁSTICAS. Florianópolis. 2008. Disponível em: http://www.anpap.org.br/2008/artigos/180.pdf. Acesso em: 26 jun. 2013.

STIEGLER, Bernard. Acting Out, Crogan. Stanford: Stanford University Press, 2007.

VARELA, F.; THOMPSOM; ROSCH, E. A mente incorporada. Porto Alegre: Artmed, 2003.

WEIBEL, Peter. Entrevista à INTERACT - Revista digital de Arte, Cultura e Tecnologia, (maio de 2005). Instituto do Cinema Audiovisual e Multimédia. CECL - Centro de Estudos de Comunicação e Linguagens da Universidade Nova de Lisboa. Disponível em: http://www.interact.com.pt/memory/13/ Interact13_home.html. Acesso em: 19 jun. 2013.

Submetido para avaliação em 01 de maio de 2012.

Aprovado para publicação em 11 de novembro de 2013.

Fúlvia da Silva Spohr: Professora e Tutora da Rede Gaúcha de Ensino Superior a Distância - Porto Alegre - RS Brasil. E-mail: f.spohr@ig.com.br

Maria Cristina Villanova Biazus: Professora da Universidade Federal do Rio Grande do Sul - Porto Alegre - RS Brasil. E-mail: mcbiazus@gmail.com 